\title{
Mixed Resistive Unbalance and Winding Inter-Turn Faults Model of Permanent Magnet Synchronous Motors
}

\author{
Julio-César Urresty*, Jordi-Roger Riba**, Luís Romeral*, Juan-Antonio Ortega*
}

*Electronic Engineering Department, Universitat Politècnica de Catalunya, Universitat Politècnica de Catalunya, 08222

Terrassa, Spain.

**Corresponding author: Electrical Engineering Department, Universitat Politècnica de Catalunya, 08700 Igualada, Spain, Tel.: +34 938035300; fax: +34 938031589. E-mail address: riba@ee.upc.edu (J.-R. Riba)

\begin{abstract}
This work analyzes the behavior of surface-mounted permanent magnet synchronous motors (SPMSMs) operating under stator faults. The studied faults are resistive unbalance and winding inter-turn short circuits, which may lead to unbalanced conditions of the motor. Both faults may reduce motor efficiency and performance and produce premature ageing. This work develops an analytical model of the motor when operating under stator faults. By this way, the theoretical basis to understand the effects of resistive unbalance and stator winding inter-turn faults in SPMSMs is settled. This work also compares two methods for detecting and discriminating both faults. For this purpose, a method based on the analysis of the zero-sequence voltage component is presented, which is compared to the traditional method, i.e. the analysis of the stator currents harmonics. Both simulation and experimental results presented in this work show the potential of the zero-sequence voltage component method to provide helpful and reliable data to carry out a simultaneous diagnosis of resistive unbalance and stator winding inter-turn faults.
\end{abstract}

\section{KEYWORDS}

Resistive unbalance, inter-turn short-circuit, zero-sequence voltage component, fault diagnosis, harmonic analysis, permanent magnet synchronous motor.

\section{NOMENCLATURE}

$\left[V_{s f, a b c}\right]$ : Stator voltage matrix of a faulty machine.

$\left[V_{0}\right]$ : Zero-sequence voltage component matrix.

$V_{0}$ : Zero-sequence voltage component measured between the center of the stator windings and the dc mid-point of the inverter.

$V_{a}$ : $\quad$ Phase-to-neutral voltage of phase $a$.

$\left[i_{s f, a b c}\right]$ : Stator currents matrix of a faulty machine.

$i_{a}: \quad$ Stator current in phase $a$.

$i_{f:}$ : $\quad$ Circulating current in the shorted turns.

$R_{s}$ : $\quad$ Per phase stator resistance.

$\left[R_{s f}\right]$ : Stator resistance matrix of a faulty machine.

$\left[R_{s f, s a t}\right]$ : Stator resistance matrix of a faulty machine including saturation effects.

$R_{f}$ : Resistance that models the insulation failure.

$\left[L_{s f}\right]$ : Stator inductance matrix of a faulty machine.

$\left[L_{s f, s a t}\right]$ : Stator inductance matrix of a faulty machine including saturation effects.

$L: \quad$ Per phase stator self-inductance.

$M$ : $\quad$ Mutual inductance between stator phases.

$\left[\lambda_{s f, a b c}\right]: \quad$ Stator three-phase magnetic flux matrix of a faulty machine.

$\left[\lambda_{P M f, a b c}\right]$ :Stator three-phase magnetic flux matrix of a faulty machine due to permanent magnets.

$\lambda_{P M:} \quad$ Peak strength of permanent magnet flux.

$\lambda_{P M a}: \quad$ Flux linkage in phase $a$ due to permanent magnets.

$\lambda_{P M, l}$ : Fundamental magnet flux.

$\lambda_{P M, h}: \quad h$-th harmonic of the magnet flux.

$\lambda_{P M, 0}$ : Stator zero-sequence flux component due to permanent magnets.

$\lambda_{a:} \quad$ Flux linkage in phase $a$.

$p$ : $\quad$ Number of pole pairs.

$v$ : Ratio between the number of shorted turns and the total turns per phase.

$k$ : $\quad$ Resistive unbalance ratio.

\section{INTRODUCTION}

Permanent magnet synchronous motors (PMSMs) are gaining popularity in critical applications where high-speed operation, precise torque control, compactness and high efficiency are required [1-3]. In these applications it is highly desired to dispose of 
an on-line, reliable and cost-effective diagnosis method to detect stator faults at an early stage. Fault prediction and diagnosis allows increasing electric machines performance and raising their lifespan, thus lowering maintenance costs due to unscheduled downtime [4-5], while ensuring optimum reliability, safe operation and timely maintenance [6].

Under asymmetrical operation, ac machines absorb unbalanced line currents which decrease their performance [7]. As both resistive unbalance and stator-winding inter-turn faults typically take place in only one of the three phases, they produce an asymmetry of the machine impedance [8-9], thus generating similar symptoms [10]. Therefore, resistive unbalance and interturn faults can be detected by analyzing negative-sequence phase currents [10]. Additionally, it is well-known that effects such as voltage unbalances and machine saturation may influence the amplitude of the negative-sequence currents [11].

In a three-phase motor the phase resistances should be as balanced as possible, otherwise a resistive unbalance is generated. Unbalanced connections occur frequently in industry. Usually they are due to corrosion or contamination problems as well as to loose cable connection when an inadequate locking torque is applied to the connection lugs. Moreover, vibrations and the thermal cycling process (contraction and expansion of the nut and bolt connection due to the heat generated because of the high contact resistance) may deteriorate the connection [12]. Poor contacts may generate local overheating, unbalanced voltages and currents as well as electrical failures such as short-circuits or open-circuits [13]. Unbalanced conditions generate negativesequence voltages and currents that have a negative impact on the motor efficiency and performance and may lead to excessive thermal stress. Furthermore, voltage unbalance may generate a current unbalance several times larger than the magnitude of voltage unbalance. The impedance unbalance may increase with time because of the unbalanced heating of the stator [14].

Stator windings failures are among the most frequent faults in ac machines [15]. They have been widely studied in the last few years [16-18]. These faults are related to stator windings insulation degradation, being one of the most difficult failures to identify [19]. When dealing with PMSMs, inter-turn short-circuits may result in stator over currents that create a magnetic flux opposed to the natural flux of the permanent magnets. This reversed flux may partially demagnetize the rotor magnets [20].

In most of the technical bibliography, resistive unbalance and inter-turn faults are considered independently [13], except in [9] where both faults are detected and distinguished one from the other when dealing with induction motors. The analysis carried out in [9] is based on measuring both the amplitude and the phase angle of the negative-sequence stator currents and the zerosequence voltage component (ZSVC). However, [9] does not analyze the spectral content of neither the stator currents nor the ZSVC, as proposed in this paper. In induction motors, current signature analysis (MCSA), which is based on studying the spectral content of the currents absorbed by the motor [21], is proved to be one of the most applied and effective methods for fault diagnosis purposes.

The primary objective of this work is to study both resistive unbalance and inter-turn faults in PMSMs, as well as to provide a fault detection method for distinguishing them, even when fed by a voltage-source inverter. First, an analytical model of the PMSM which accounts for both resistive unbalance and winding inter-turn faults is derived. Next, the behavior of two fault detection methods is compared. The first one, i.e. the reference or traditional method, is based on the analysis of the third harmonic amplitude of the stator currents for different operating points of the SPMSM. The second method is based on the analysis of the first harmonic of the ZSVC. The advantages and disadvantages of both methods are studied and compared.

The proposed identification system may be easily extended to both stationary and non-stationary conditions since it is based on analyzing the stator currents and the ZSVC spectra. Under non-stationary conditions, i.e. when the machine operates under variable speed or load conditions, the harmonics of interest of both the stator currents and the ZSVC may be tracked by applying suitable algorithms such as the Vold-Kalman filtering order tracking algorithm as done in [22].

To our knowledge, the effects of high-resistance faults have not been studied in PMSMs, and have been little studied in ac machines. The results of this work allow carrying out machine maintenance more efficiently, since the analyzed faults may be detected and identified in its early stage.

This paper is divided into six sections. Following the introduction, Section 3 presents a mathematical model of the PMSM that accounts for both resistive unbalance and inter-turn faults, from which the effects of such faults are derived. Section 4 details the experimental setup used to carry out the experimental tests. Simulation and experimental results are presented in Section 5, jointly with a detailed study of the evolution of the analyzed harmonics amplitudes as a function of the speed and load conditions of the PMSM. Finally, conclusions are stated in Section 6.

\section{MODEL OF THE SPMSM CONSIDERING RESISTIVE UNBALANCE AND INTER-TURN FAULTS}

In this section the model of a healthy and a faulty surface-mounted permanent magnet synchronous motor (SPMSM) with resistive unbalance and stator windings inter-turn faults is derived. Modeling of SPMSMs operating under these types of faults is the first stage to understand their effects and to develop fault detection methods.

Both the actual speed of the SPMSM and the ratio $v=n / N$, between the number $n$ of short-circuited inter-turns and the total number of turns $N$ in a certain phase, greatly affects the severity of inter-turn short-circuit faults. The current through the $n$ short-circuited turns is designated as $i_{f}$ while $R_{f}$ is a resistance whose value depends on the fault severity. Lower values of $R_{f}$ indicate harshest inter-turn short-circuit conditions.

The electrical equations of a three-phase faulty SPMSM - subscript $f$ - with resistive unbalance in phase $a$ and inter-turn faults in phase $b$ expressed in the $a b c$ reference frame may be expressed similarly to [23-24]

$$
\left[V_{s f, a b c}\right]=\left[R_{s f}\right] \cdot\left[i_{s f, a b c}\right]+\left[\lambda_{s f, a b c}^{,}\right]+\left[V_{0}\right]
$$

where the symbol ' indicates the time derivative and 


$$
\begin{aligned}
& {\left[\lambda_{s f, a b c}\right]=\left[L_{s f}\right]\left[i_{s f, a b c}\right]+\left[\lambda_{P M, f, a b c}\right]}
\end{aligned}
$$

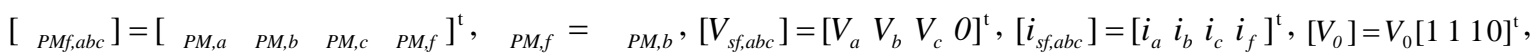

$$
\begin{aligned}
& {\left[L_{s f}\right]=\left[\begin{array}{cccc}
L & M & M & -v M \\
M & L & M & -v L \\
M & M & L & -v M \\
v M & v L & v M & -v^{2} L
\end{array}\right]}
\end{aligned}
$$

where the resistance matrix $\left[R_{s f}\right]$ has been adapted according to the unbalanced term $R_{s, a}=k R_{s}$, being $k$ a multiplying factor that modifies the resistance in phase $a$. Hence, the resistance matrix results in,

$$
\left[R_{s f}\right]=\left[\begin{array}{cccc}
k R_{s} & 0 & 0 & 0 \\
0 & R_{s} & 0 & -v R_{s} \\
0 & 0 & R_{s} & 0 \\
0 & v R_{s} & 0 & -v R_{s}-R_{f}
\end{array}\right]
$$

The flux linkage $\left[\lambda_{P M, a b c}\right]$ expressed in the $a b c$ reference frame due to the permanent magnets taking into account the spatial harmonics (owing to the geometrical configuration of the rotor permanent magnets or non-sinusoidal stator windings configuration) is as follows [23]

where $h$ is the harmonic order.

$$
\left\{\begin{array}{l}
\lambda_{P M, a}=\lambda_{P M, I} \cos (\theta)+\sum_{h=1,3,5} \lambda_{P M, h} \cos \left(h \theta-\theta_{v}\right) \\
\lambda_{P M, b}=\lambda_{P M, I} \cos \left(\theta-2 \frac{\pi}{3}\right)+\sum_{h=1,3,5, \ldots} \lambda_{\mathrm{PM}, \mathrm{h}} \cos \left(h \theta-\theta_{v}-2 h \frac{\pi}{3}\right) \\
\lambda_{\mathrm{PM}, \mathrm{c}}=\lambda_{P M, I} \cos \left(\theta+2 \frac{\pi}{3}\right)+\sum_{h=1,3,5, \ldots} \lambda_{\mathrm{PM}, \mathrm{h}} \cos \left(h \theta-\theta_{v}+2 h \frac{\pi}{3}\right)
\end{array}\right.
$$

Adding the first three rows of equation (1) and having into account equation (2), the expression of the ZSVC measured between the center of the stator windings and the dc mid-point of the inverter is obtained as follows

$$
V_{0}=\frac{1}{3}\left(V_{a}+V_{b}+V_{c}\right)-\frac{1}{3} R_{s}(k-1) i_{a}+\frac{1}{3} v R_{s} i_{f}+\frac{1}{3} v(L+2 M) i^{\prime}{ }_{f}-\lambda_{P M, 0}
$$

where $\quad \lambda_{P M, 0}=\frac{1}{3}\left(\lambda_{P M, a}+\lambda_{P M, b}+\lambda_{P M, c}\right)$

The ZSVC measured as in (3) is not decoupled from the motor controller effects. These influences are almost totally removed by measuring the ZSVC between the neutral point of the stator windings and the central point of a three-phase balanced resistor network connected between the inverter and the motor as detailed in $[25,26]$ thus resulting in

$$
V_{0, \text { measured }}=-\frac{1}{3} R_{s}(k-1) i_{a}+\frac{1}{3} v R_{s} i_{f}+\frac{1}{3} v(L+2 M) i_{f}{ }_{f}-\lambda_{P M, 0}
$$

The first three terms in (4) are mainly influenced by the first harmonic of the supply frequency. Contrarily, the last term which is not related to the studied faults, primarily depends on the third harmonic component due to the particular geometry of the permanent magnets [23]. Hence, from the study of the first harmonic of the ZSVC it is possible to detect both resistive unbalance and inter-turn faults.

\subsection{SPMSM with resistive unbalance and inter-turn faults including saturation effects}

It is well known that core saturation generates harmonic frequencies in the air gap flux distribution. Hence, saturation effects lead to odd harmonics in the experimental current spectrum [15]. A straightforward manner to approximate the magnetic saturation curve is by means of a polynomial approximation,

$$
B=\sum_{m=1,3,5, \ldots} k_{m} H^{m}
$$

where (5) only accounts for the odd harmonics since the even ones are cancelled due to the odd symmetry of the $B$ - $H$ curve.

Neglecting the saturation effects, the linear magnetic flux $\lambda_{L}$ through a phase winding is as follows

$$
\lambda_{L}=k_{\text {wind }} B_{L}=\mu k_{\text {wind }} H
$$

where $k_{\text {wind }}$ is a winding factor whose value depends on the particular type of winding and $\mu$ is the magnetic permeability of the ferromagnetic core. From (6) it results in

$$
H=\frac{\lambda_{L}}{\mu k_{\text {wind }}}
$$

By taking into account the saturation effects and equation (5), the expression of the saturated flux $\lambda_{\text {sat }}$ through a phase winding is obtained 


$$
\lambda_{\text {sat }}=k_{\text {wind }} B(H)=\mu k_{\text {wind }} \sum_{m=1,3,5, \ldots} k_{m} H^{m}
$$

From (7) and (8) it results in

$$
\lambda_{\text {sat }}=\sum_{m=1,3,5, \ldots} k_{\lambda m} \lambda_{L}^{m}
$$

where $k_{\lambda m}=\frac{k_{m}}{\mu^{m} k_{\text {wind }}^{m-1}}$.

By including (4) in (1), the expression of the phase fluxes under faulty conditions are obtained as

$$
\left\{\begin{array}{c}
\lambda_{a}=L i_{a}+M i_{b}+M i_{c}+\frac{1}{3} v(L-M) i_{f}+\lambda_{P M, a}-\lambda_{P M, O} \\
\lambda_{b}=M i_{a}+L i_{b}+M i_{c}-\frac{2}{3} v(L-M) i_{f}+\lambda_{P M, b}-\lambda_{P M, O} \\
\lambda_{c}=M i_{a}+M i_{b}+L i_{c}+\frac{1}{3} v(L-M) i_{f}+\lambda_{P M, c}-\lambda_{P M, o} \\
\lambda_{f}=v M i_{a}+v L i_{b}+v M i_{c}-v^{2} L i_{f}+v \lambda_{P M, b}
\end{array}\right.
$$

By performing the time derivative of (10) and having into account the saturation effects by means of (9) until grade 7 it results in

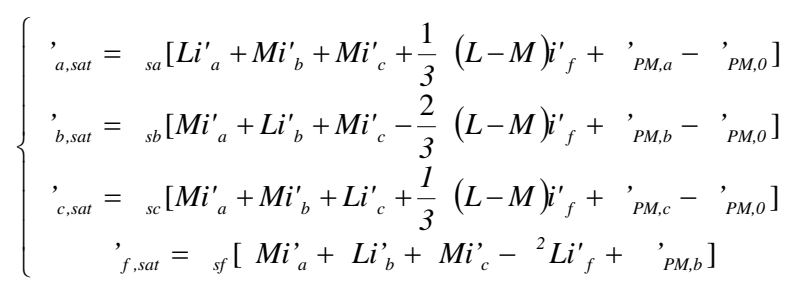

where $\zeta_{\text {sphase }}=k_{\lambda 1}+3 k_{\lambda 3} \lambda_{\text {phase }}^{2}+5 k_{\lambda 5} \lambda_{\text {phase }}^{4}+7 k_{\lambda 7} \lambda_{\text {phase }}^{6}$ and phase states for $a, b, c$ or $f$. Note that saturation effects are neglected when $k_{\lambda 3}, k_{\lambda 5}$ and $k_{\lambda 7}$ are set to zero. By including (11) in (1) it results in

$$
\left[V_{s f a b c}\right]=\left[R_{s f, s a t}\right] \cdot\left[i_{s f a b c}\right]+\left[L_{s f, s a t}\right]\left[i_{s f, a b c}^{\prime}\right]+\left[e_{s a t}\right]
$$

Note that (12) has into account the saturation effects, and their matrixes are expressed as

$$
\begin{gathered}
{\left[R_{s f, s a t}\right]=\left[\begin{array}{cccc}
-\frac{R_{s}}{3}(2 k+1) & 0 & 0 & \frac{1}{3} v R_{s} \\
-\frac{R_{s}}{3}(k-1) & R_{s} & 0 & -\frac{2}{3} v R_{s} \\
-\frac{R_{s}}{3}(k-1) & 0 & R_{s} & \frac{1}{3} v R_{s} \\
0 & v R_{s} & 0 & -v R_{s}-R_{f}
\end{array}\right],\left[L_{s f, s a t}\right]=\left[\begin{array}{cccc}
\zeta_{a s} L & \zeta_{a s} M & \zeta_{a s} M & \frac{1}{3} v \zeta_{a s}(L-M) \\
\zeta_{b s} M & \zeta_{b s} L & \zeta_{b s} M & -\frac{2}{3} v \zeta_{b s}(L-M) \\
\zeta_{c s} M & \zeta_{c s} M & \zeta_{c s} L & \frac{1}{3} v \zeta_{c s}(L-M) \\
v \zeta_{f s} M & v \zeta_{f s} L & v \zeta_{f s} M & -v^{2} \zeta_{f s} L
\end{array}\right] \text { and }} \\
{\left[e_{s a t}\right]=\left[\begin{array}{c}
\lambda_{P M, a}^{\prime} \zeta_{a s}-\lambda_{P M, 0}^{\prime} \zeta_{a s} \\
\lambda_{P M, b}^{\prime} \zeta_{b s}-\lambda_{P M, 0}^{\prime} \zeta_{b s} \\
\lambda_{P M, c}^{\prime} \zeta_{c s}-\lambda_{P M, 0} \zeta_{c s} \\
v \lambda_{P M, b}^{\prime} \zeta_{f s}
\end{array}\right] .}
\end{gathered}
$$

According to (12), resistive unbalance faults generate negative-sequence components due to the loss of symmetry in $\left[R_{s f, s a t}\right]$. In a faulty machine the abovementioned conditions may result in third harmonic components in the current spectrum even with sinusoidal feeding. It is so because the negative-sequence components may cause a phase of the machine to work instantaneously beyond the knee point of the $B-H$ curve, thus generating saturation and third harmonic components in the current spectrum.

Shorted turns also generate negative-sequence components due to the lack of symmetry in matrixes $\left[R_{s f, s a t}\right]$ and $\left[L_{s f, s a t}\right]$. Additionally, the circulating current $i_{f}$ has a third harmonic component which is greatly influenced by the geometry of the rotor magnets [23]. Equation (12) predicts a link between the fault current $i_{f}$ and the stator currents $i_{a}, i_{b}$ and $i_{c}$. Hence, the stator currents spectrum must present a third harmonic component originated by the shorted-turns which is not due to saturation effects since $i_{f}$ has a demagnetizing effect [23].

Summarizing, the first harmonic of the ZSVC and the third one of the stator currents are proposed in this work to detect and discriminate resistive unbalance and inter-turn faults.

\section{EXPERIMENTAL SETUP}

A healthy and a faulty SPMSMs specially modified to deal with the studied faults were used to conduct the experimental tests. Both motors have access to the neutral point of the stator windings. These motors were loaded with an additional SPMSM. Additional features of the motors studied are summarized in Table I. 
Table I Features of the Analyzed SPMSMs

\begin{tabular}{lc}
\hline Manufacturer & ABB \\
Converter model & DGV 700 \\
Rated voltage & $380 \mathrm{Vac}$ \\
Rated current & $2.9 \mathrm{~A}$ \\
Rated torque & $2.3 \mathrm{Nm}$ \\
Rated speed & $6000 \mathrm{r} / \mathrm{min}$ \\
Poles pairs & 3 \\
Stator slots & 18 \\
$N$ & 144 turns/phase \\
$R_{S}$ & $\Omega(1.1 \% \mathrm{unbalance})$ \\
$L$ & $11.6 \mathrm{mH}$ \\
$M$ & $4.45 \mathrm{mH}$ \\
\hline
\end{tabular}

The modified SPMSM allows adjusting the number of inter-turns in short circuit, since it has some turns with connections which are accessible from outside the motor. During experimental tests, these stator turns can be short-circuited and the fault current can be measured, as illustrated in Fig. 1. Whereas the three stator currents were measured by means of three Tektronix A622 ac/dc current probes, a LEM AV 100-50 voltage transducer was used to measure the ZSVC. The stator resistances of the healthy motor were balanced to $1.50 \Omega$. A $1 \Omega$ resistance was connected in series with phase $a$ of the unbalanced SPMSM. To decouple the measurements from the motor controller, the ZSVC was measured by using a three-phase wye-connected balanced resistive network as detailed in [25]. The ZSVC was measured between the neutral point of the stator windings and the central point of the three-phase balanced resistor network, as shown in Fig. 1.

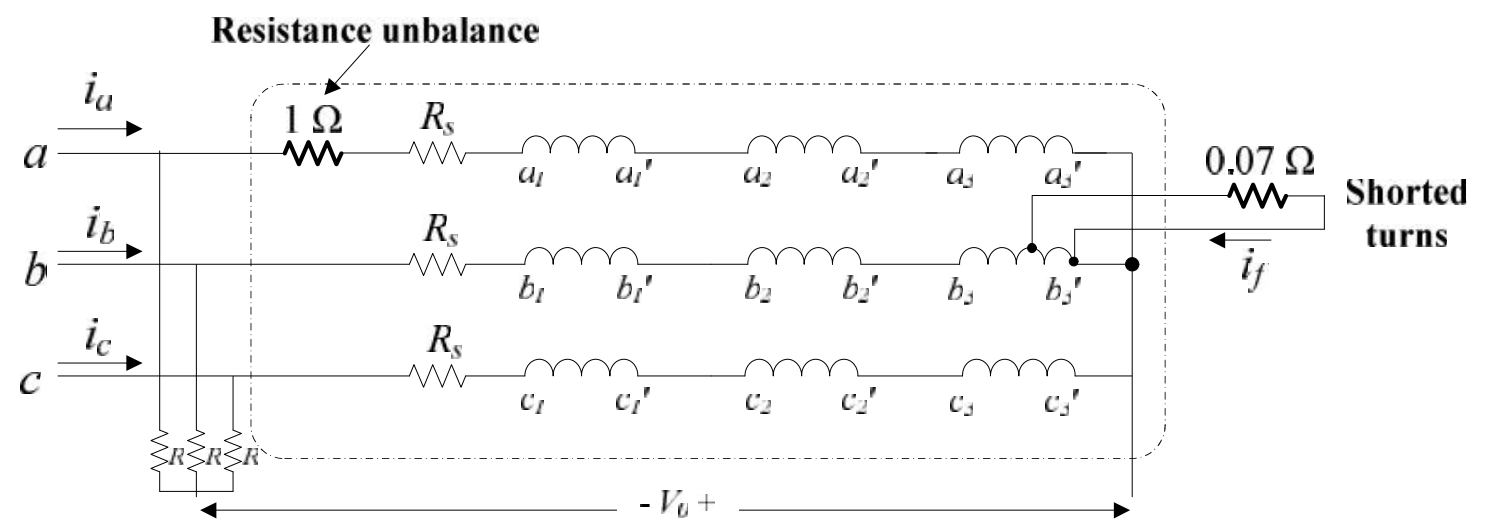

Fig. 1. Diagram of the modified stator windings showing the access to the short-circuited turns, the $1 \Omega$ resistance to produce the resistive unbalance and the three-phase resistive network used to measure the ZSVC.

A multifunction DAQ NI PCI-6251 board with 16 input channels and 16 bits resolution was used for data acquisition. The stator currents were acquired by means of three A622 ac/dc current probes. The ZSVC was measured by means of a LEM AV $100-50$ voltage transducer with rated voltage $50 \mathrm{~V}_{\mathrm{RMS}}$.

\section{RESULTS}

Simulation and experimental results are compared in this section. Simulations have been carried out according to equations derived in Section III, which have been implemented by means of Matlab/Simulink. Results presented in this section are based on a healthy motor $(\mathrm{H})$, a motor with a resistive unbalanced in phase $a(\mathrm{RU} a)$, a motor with four turns in short circuit in phase $b$ $(\mathrm{SC} b)$ and a motor combining both faults ( $\mathrm{RU} a+\mathrm{SC} b)$.

The input data required to perform the simulations (flux harmonics, saturation curve, etc.) according to (12) were obtained from the finite elements model detailed in $[1,23]$. The study of both types of faults is performed by analyzing the amplitude of the third harmonic of the stator currents and the first harmonic of the ZSVC.

\subsection{Results generalization}

In this subsection, in order to diagnose and distinguish both types of faults, the harmonics amplitudes when the SPMSM operates under a wide range of speed and load operating points are analyzed. Fig. 2 shows a phasor diagram including the fault current $i_{f}$ and phase currents $i_{a}$ and $i_{b}$. 


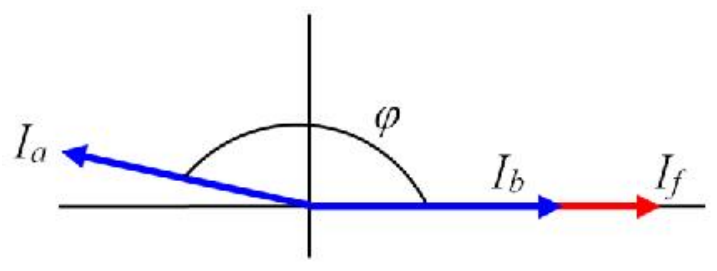

Fig. 2. Diagram showing the fault current if and the line currents $i_{a}$ and $i_{b}$.

From (4) and Fig. 2, the first harmonic amplitude of the ZSVC may be rewritten as a function of the speed and the load level as,

$$
V_{0, \text { measured }}^{2}=\left(-\frac{1}{3} R_{s}(k-1) I_{a} \cos \varphi+\frac{1}{3} v R_{s} I_{f}\right)^{2}+\left(-\frac{1}{3} R_{s}(k-1) I_{a} \sin \varphi+\frac{1}{3} v \omega(L+2 M) I_{f}\right)^{2}
$$

where $\varphi$ is the phase shift between the stator current in phase $a$ and current $i_{f}$, and $\omega$ is the electrical angular frequency. Fig. 3 shows the behavior of the first harmonic amplitude of the ZSVC as predicted by (13) when the faulty SPMSM with resistive unbalance operates under different speed and load conditions. It shows that the amplitude of the first harmonic is nearly independent of the motor speed and it is proportional to the load level.

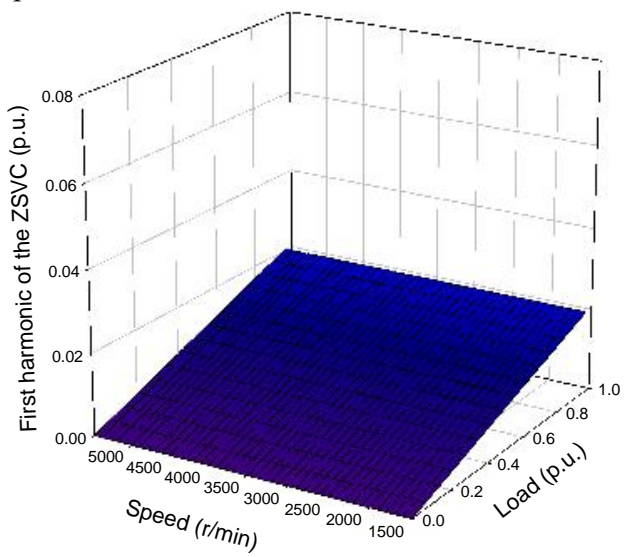

Fig. 3. Resistive unbalance in phase $a(\mathrm{RU} a$ ). Evolution of the first harmonic amplitude of the ZSVC when the analyzed SPMSM operates under different speed and load conditions. Simulation results.

Fig. 4 shows the evolution of the first harmonic amplitude of the ZSVC as predicted by (13) when the SPMSM with four shorted-turns operates under different speed and load conditions. It shows that the amplitude of the first harmonic is nearly independent of the load level and increases almost linearly with speed. The deviation from the linearity is due to the inductive effect of the last term in (13), which becomes important at high speeds.

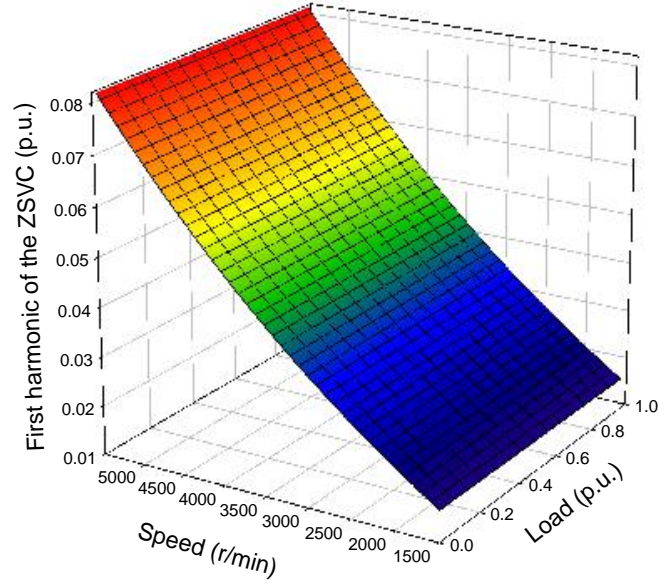

Fig. 4. Four short-circuited turns in phase $b(\mathrm{SC} b)$. Evolution of the first harmonic amplitude of the ZSVC when the analyzed SPMSM operates under different speed and load conditions. Simulation results. 
Fig. 5 plots the behavior of the first harmonic amplitude of the ZSVC when the SPMSM with both resistive unbalance and four shorted-turns operates under different speed and load conditions. It indicates that as the load increases the linearity of the response curve decreases due to the combined effects of both resistive unbalance and shorted-turns. While the resistive unbalance produces a linear increase of the ZSVC first harmonic amplitude with the load level, shorted-turns faults produce a non-linear increase with the motor speed.

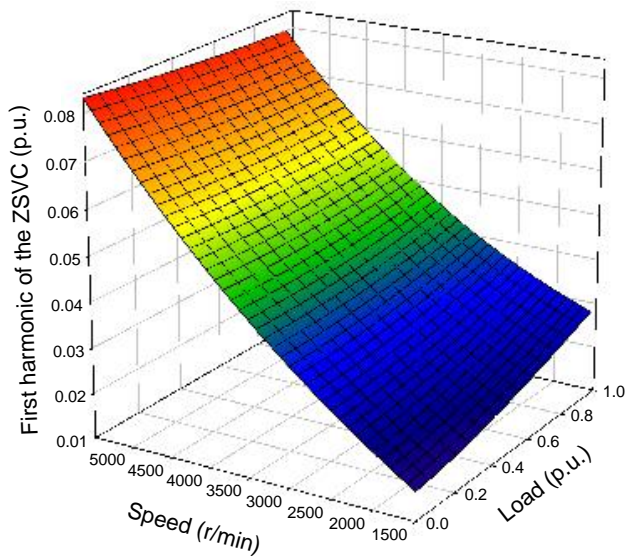

Fig. 5. Resistive unbalance in phase $a$ and four short-circuited turns in phase $b(\mathrm{RU} a+\mathrm{SC} b)$. Evolution of the first harmonic amplitude of the ZSVC when the analyzed SPMSM operates under different speed and load conditions. Simulation results.

\subsection{Results at low speed operation and varying torque}

Figs. $6 \mathrm{a}$ and $6 \mathrm{~b}$ show, respectively, simulation and experimental results of the third harmonic of the stator current in phase $a$ when the motors $\mathrm{H}, \mathrm{RU} a, \mathrm{SC} b$ and $\mathrm{RU} a+\mathrm{SC} b$ are analyzed. All motors are tested under different load conditions when operating at low speed, $1500 \mathrm{r} / \mathrm{min}$.
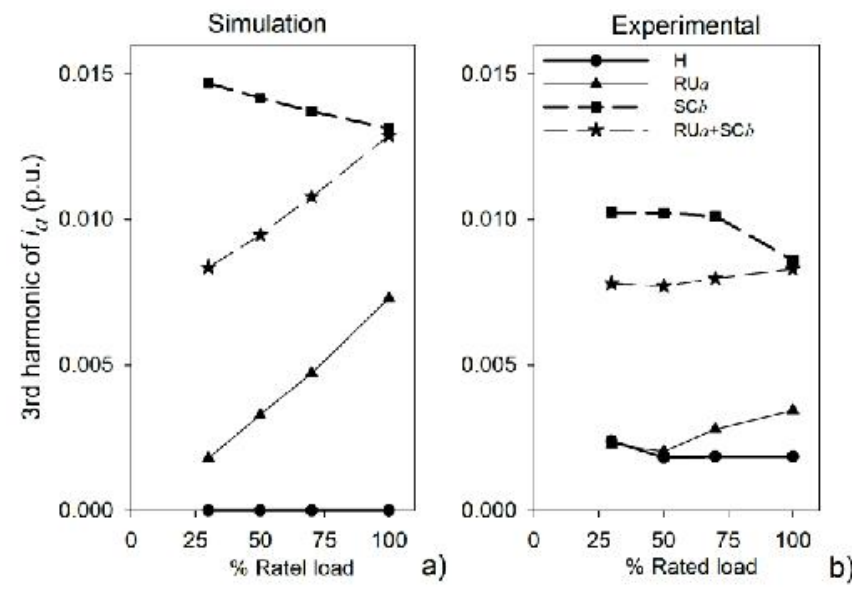

Fig. 6. Third harmonic components of the stator current in p.u. when operating at $1500 \mathrm{r} / \mathrm{min}$. a) Simulation results. b)

Experimental results.

Figs. 7a and 7b show, respectively, simulation and experimental results of the first harmonic component of the ZSVC when the motors $\mathrm{H}, \mathrm{RU} a, \mathrm{SC} b$ and $\mathrm{RU} a+\mathrm{SC} b$ operate under different load levels at $1500 \mathrm{r} / \mathrm{min}$. 


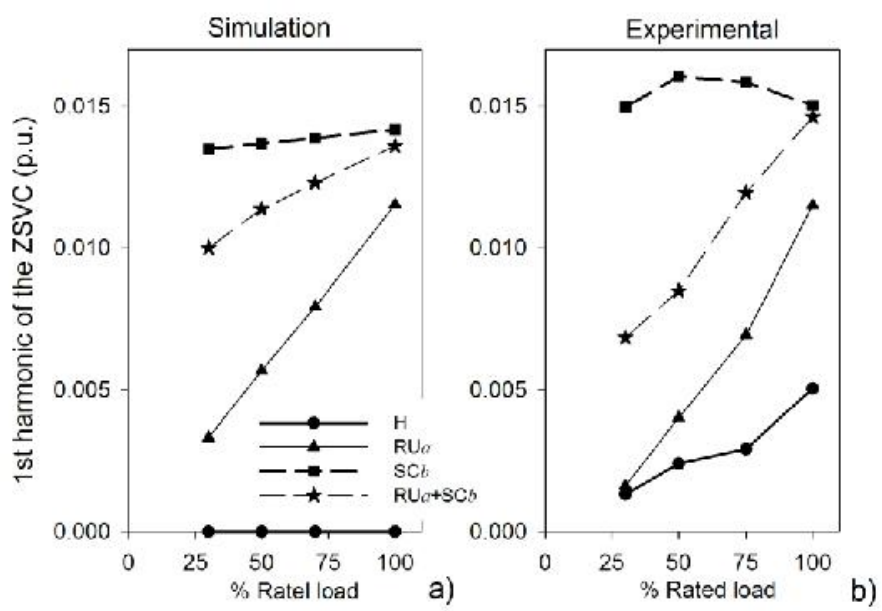

Fig. 7. First harmonic components of the ZSVC in p.u. when operating at $1500 \mathrm{r} / \mathrm{min}$. a) Simulation results. b) Experimental results.

Simulation results presented in Figs. 6 and 7 show a similar behavior of the third harmonic of the currents and the first harmonic of the ZSVC. Additionally, experimental results show better performance of the ZSVC-based method compared to the currents-based method results. This is in part due to the fact that the PMSM controller may inject current harmonics which may partially distort the theoretical results [27]. Conversely, the ZSVC-based method is decoupled from the motor controller effects [25].

In case of resistive unbalance, when analyzing its behavior under different load conditions, it can be approximated by a straight line intersecting the origin, as deduced from the first term in (4). In case of short-circuited turns, both the third current harmonic and the first ZSVC harmonic are due to the current $i_{f}$ circulating through the shorted-turns, which is greatly influenced by the actual speed of the SPMSM [23]. Hence, the behavior of these harmonics is little affected by the load of the motor. However, the third current harmonic has a more complex behavior. In case of combining both faults (RUa+SCb), the third harmonic of the stator currents and the first one of the ZSVC have a linear behavior with respect to the load level. However, in this case the resulting straight line does not pass through the origin due to the offset introduced by the current $i_{f}$, as explained in (4).

\subsection{Results at high speed operation and varying torque}

Figs. 8a and 8b show, respectively, simulation and experimental results of the third harmonic of the stator current in phase $a$ when the motors $\mathrm{H}, \mathrm{RU} a, \mathrm{SC} b$ and $\mathrm{RU} a+\mathrm{SC} b$ are analyzed. All motors are tested under different load levels when operating at $5500 \mathrm{r} / \mathrm{min}$.
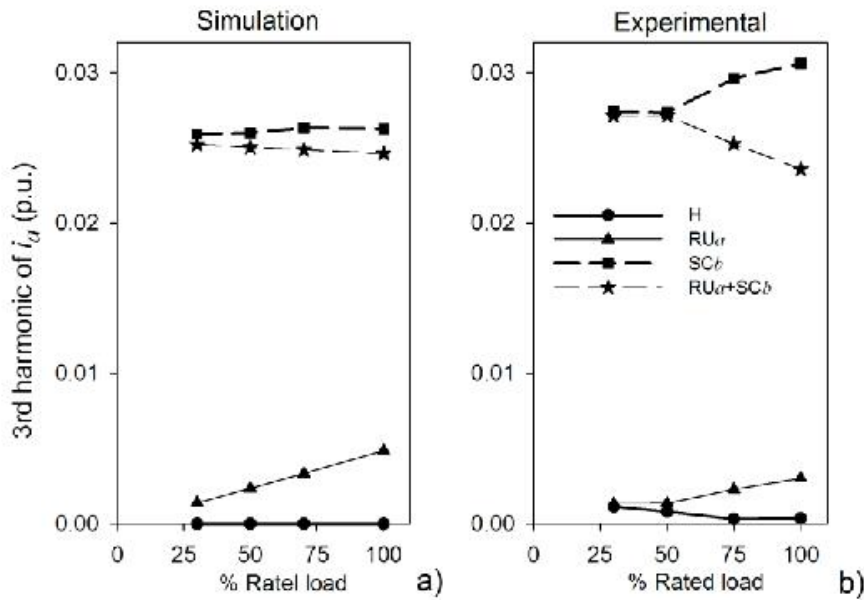

Fig. 8. Third harmonic components of the stator current in p.u. when operating at $5500 \mathrm{r} / \mathrm{min}$. a) Simulation results. b) Experimental results.

Figs. 9a and 9b show, respectively, simulation and experimental results of the first harmonic component of the ZSVC when the motors $\mathrm{H}, \mathrm{RU} a, \mathrm{SC} b$ and $\mathrm{RU} a+\mathrm{SC} b$ operate under different load levels at $5500 \mathrm{r} / \mathrm{min}$. 

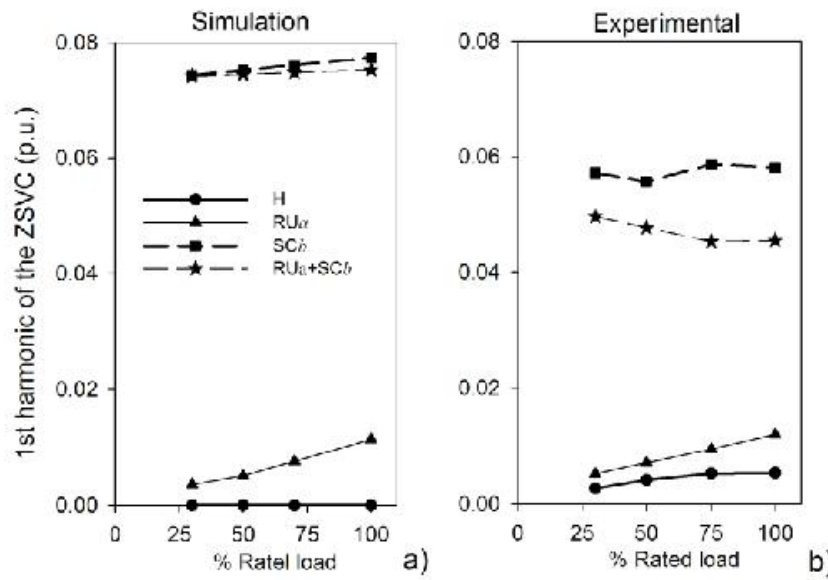

Fig. 9. First harmonic components of the ZSVC in p.u. when operating at $5500 \mathrm{r} / \mathrm{min}$. a) Simulation results. b) Experimental results.

Results from Figs. 8 and 9 indicate that at high speed, the resistive unbalance presents a quasi-linear behavior with respect to the load level (for both the third harmonic of the stator currents and the first one of the ZSVC), as in the case of low speed operation. In case of shorted-turns, the harmonics amplitudes are almost independent of the load level. Additionally they are higher at high speed than at low speed operation since the circulating current $i_{f}$ increases with the motor speed. When dealing with both faults simultaneously ( $\mathrm{RU} a+\mathrm{SC} b)$, the behavior of the harmonic frequencies is similar to that of the shorted-turns. It is so because the amplitude of the $i_{f}$ current harmonics prevails over the amplitude of the harmonics due to resistive unbalance.

\subsection{Results at rated load and varying speed}

Figs. 10 show simulation and experimental results of the third harmonic of the stator current in phase $a$ when the motors $\mathrm{H}$, $\mathrm{RU} a, \mathrm{SC} b$ and $\mathrm{RU} a+\mathrm{SC} b$ are analyzed. All motors are tested under different speeds when operating at rated load.
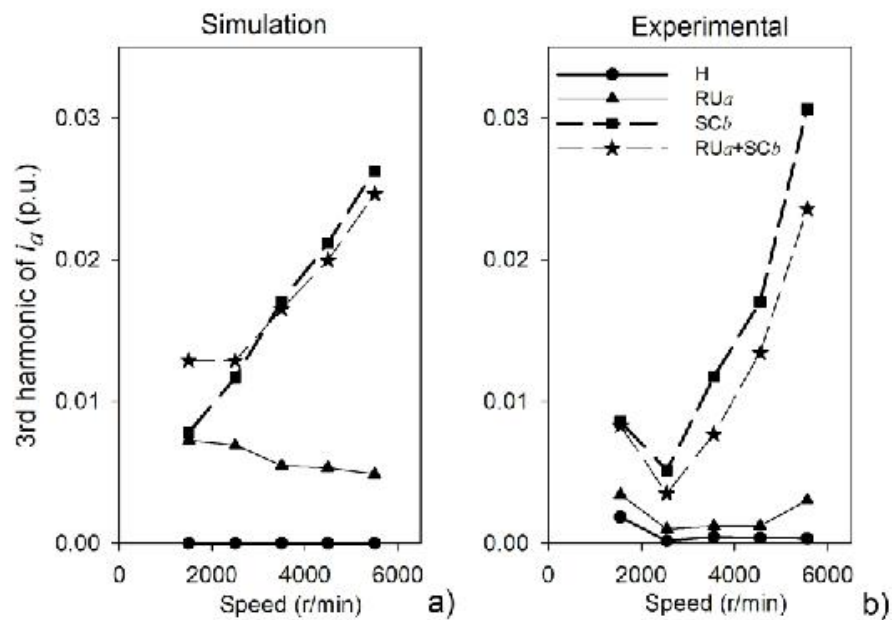

Fig. 10. Third harmonic components of the stator current in p.u. when operating at rated load. a) Simulation results. b) Experimental results.

Figs. 11 show simulation and experimental results of the first harmonic of the ZSVC when the SPMSMs are tested at rated load under different speed conditions. 

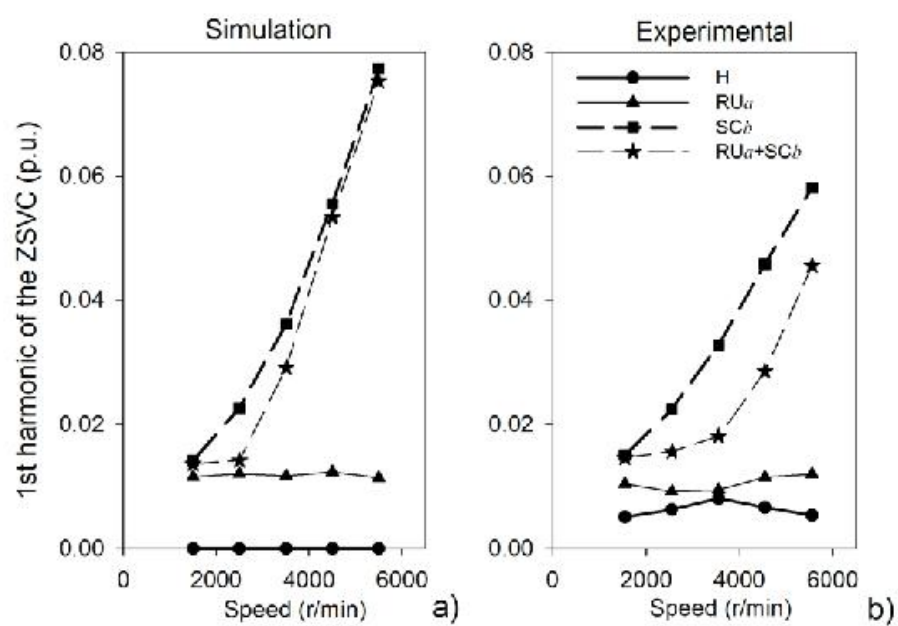

Fig. 11. First harmonic components of the ZSVC in p.u. when operating at rated load. a) Simulation results. b) Experimental results.

From Figs. 10 and 11 it is deduced that in case of resistive unbalance the amplitudes of the first harmonic of the stator currents and the first harmonic of the ZSVC are nearly independent of the speed. This result is corroborated by (4), since the mathematical expression of the ZSVC is independent of the actual speed of the SPMSM. However, in case of shorted-turns, the behavior of the analyzed harmonics is almost linear with the speed. The second and third terms in (4) are a function of the current $i_{f}$, whereas this last increases with the motor speed because of the induction of the rotor magnets [23]. However, when both faults occur simultaneously, the linearity between the harmonics amplitudes and the speed decreases.

According to the experimental results presented in this work, the third harmonic of the stator currents has a similar behavior than that of the first harmonic of the ZSVC. Hence, the evolution of the third harmonic of the stator currents with respect to the load level and the motor speed should be similar to the ones shown in Figs. 2-4.

Summarizing, the results presented in this section show that it is possible to diagnose and discriminate resistive unbalance from stator winding inter-turn faults in SPMSMs by analyzing different operating conditions. In case of a resistive unbalance the amplitude of the analyzed harmonics remains nearly constant under changes of the motor speed, but increases linearly with the load level. Contrarily, in case of short-circuit faults, the amplitude of the studied harmonics increases linearly with the motor speed but remains nearly constant under load level changes.

As explained, results presented in Figs. 6-11 show a most similar behavior of the experimental ZSVC first harmonic with respect to simulation results than the behavior of the third harmonic of the stator currents. This is so because the ZSVC is decoupled from the motor controller, which may significantly influence the stator currents harmonics [28,29]. However, the ZSVC requires accessing to the neutral point of the stator windings as occurs in fault tolerant schemes where an extra inverter leg is added $[25,30]$.

\section{CONCLUSIONS}

Combined effects of resistive unbalance and stator windings inter-turn faults have been very little studied in general, and not studied in PMSMs in particular. In this work it is shown that both types of faults greatly influence the third harmonic amplitude of the stator currents and the first harmonic of the ZSVC. Hence, by monitoring the stator currents and/or the ZSVC under different operating conditions of the SPMSM it is possible to establish a fault diagnosis scheme which allows discriminating both types of faults. For this purpose a parametric model of the SPMSM has been established, which accounts for both types of faults. Simulation results obtained by applying the proposed model have been corroborated by means of experimental data, the possible differences have been identified and their causes explained. Although the ZSVC-based method has the drawback of requiring an accessible neutral point, its harmonic content is decoupled from the motor controller effects. Contrarily, the method based on the stator currents is easier to apply, but their harmonic content may be influenced by other parameters. Hence, as proved, the ZSVC-based method usually presents more accurate and reliable results that those obtained by analyzing the third harmonic amplitude of the stator currents. Hence, it is suggested to apply the method based on the analysis of the first harmonic of the ZSVC.

Results presented prove that both faults may be identified and discriminated by applying the criteria detailed in Table II, which summarizes the findings of this work. 
Table II Change in the third harmonic of the stator currents and in the ZSVC first harmonic amplitude

\begin{tabular}{|c|c|c|c|}
\hline & $\mathbf{R U}$ & SC & $\mathbf{R U}+\mathbf{S C}$ \\
\hline \multicolumn{4}{|l|}{ Speed increase } \\
\hline Low load & $\approx$ constant & $\approx$ linear & $\approx$ linear \\
\hline High load & $\approx$ constant & $\approx$ linear & non-linear \\
\hline \multicolumn{4}{|l|}{ Load increase } \\
\hline Low speed & $\approx$ linear & $\approx$ constant & $\approx$ linear \\
\hline High speed & $\approx$ linear & $\approx$ constant & $\approx$ constant \\
\hline
\end{tabular}

\section{ACKNOWLEDGEMENTS}

This work was supported in part by the Spanish Ministry of Science and Technology under the TRA2010-21598-C02-01 Research Project.

\section{REFERENCES}

1 Urresty JC, Riba JR, Romeral L, Garcia A (2010) A Simple 2D Finite Elements Geometry for Analyzing Surface-Mounted Synchronous Machines with Skewed Rotor Magnets. IEEE Trans Magn 46:3948-3954.

2 Ruuskanen V, Immonen P, Nerg J, Pyrhönen J (2012) Determining electrical efficiency of permanent magnet synchronous machines with different control methods. Electr Eng 94:97-106

3 Riba JR, Garcia A, Romeral L (2010) Demagnetization Diagnosis in Permanent Magnet Synchronous Motors under NonStationary Speed Conditions. Electr Pow Syst Res 80:1277-1285.

4 Cusido J, Romeral L, Ortega JA, Garcia A, Riba JR (2010) Wavelet and PDD as Fault Detection Techniques. Electr Pow Syst Res 80:915-924.

5 Ebrahimi BM, Faiz J, Roshtkhari MJ (2009) Static-, Dynamic-, and Mixed-Eccentricity Fault Diagnoses in PermanentMagnet Synchronous Motors. IEEE Trans Ind Electron 56:4727-4739.

6 Khan M, Rahman MA (2009) Development and Implementation of a Novel Fault Diagnostic and Protection Technique for IPM Motor Drives. IEEE Trans Ind Electron 56:85-92.

7 Henao H, Demian C, Capolino GA (2003) A Frequency-Domain Detection of Stator Winding Faults in Induction Machines Using an External Flux Sensor. IEEE Trans Ind Appl 39:1272-1279.

8 Toliyat HA, Lipo TA (1995) Transient analysis of cage induction machines under stator, rotor bar and end ring faults. IEEE Trans Energy Convers 10:241-7.

9 Yun J, Lee K, Lee KW, Lee SB, Yoo JY (2009) Detection and Classification of Stator Turn Faults and High-Resistance Electrical Connections for Induction Machines. IEEE Trans Ind Appl 45:666-675.

10 Behbahanifard H, Karshenas H, Sadoughi A (2008) Non-invasive On-line Detection of Winding Faults in Induction Motors -A Review. In: Proceedings of the International Conference on Condition Monitoring and Diagnosis, Beijing, China, 21-14 April 2008, pp. 188-191.

11 Kliman GB, Premerlani WJ, Koegl RA Hoeweler D (1996) A new approach to on-line turn fault detection in AC motors. In: Conference Records of the IEEE-IAS Annual Meeting, San Diego 6-10 October 1996, pp 687-93.

12 Bockstette J, Stolz E, Wiedenbrug E (2007) Upstream Impedance Diagnostic for Three-Phase Induction Motors. In: Proceedings of the IEEE International Symposium on Diagnostics for Electric Machines, Power Electronics and Drives, Cracow, Poland 6-8 September 2007, pp 411-414.

13 Yun J, Cho J, Lee SB, Yoo JY (2009) Online Detection of High-Resistance Connections in the Incoming Electrical Circuit for Induction Motors. IEEE Trans Ind Appl 45:694-702.

14 Von Jouanne A, Banerjee BB (2001) Assessment of Voltage Unbalance. IEEE Trans Power Deliver 16:782-790.

15 Nandi S (2006) Detection of Stator Faults in Induction Machines Using Residual Saturation Harmonics. IEEE Trans Ind Appl 42:1201-8.

16 Neti P, Nandi S (2009) Stator Interturn Fault Detection of Synchronous Machines Using Field Current and Rotor SearchCoil Voltage Signature Analysis. IEEE Trans Ind Appl 45:911-20.

17 Cruz SMA, Cardoso AJM (2004) Diagnosis of stator inter-turn short circuits in DTC induction motor drives. IEEE Trans Ind Appl 40:1349-1360.

18 Gandhi A, Corrigan T, Parsa L (2011) Recent Advances in Modeling and Online Detection of Stator Interturn Faults in Electrical Motors. IEEE Trans Ind Electron 58:1564-75.

19 Bellini A, Filippetti F, Tassoni C, Capolino GA (2008) Advances in Diagnostic Techniques for Induction Machines. IEEE Trans Ind Electron 55:4109-4126.

20 Kim KC, Lim SB, Koo DH, Lee J (2006) The Shape Design of Permanent Magnet for Permanent Magnet Synchronous Motor Considering Partial Demagnetization. IEEE Trans Magn 42:3485-3487. 
21 Riera-Guasp M, Cabanas MF, Antonino-Daviu JA, Pineda-Sanchez M, Garcia CHR (2010) Influence of Nonconsecutive Bar Breakages in Motor Current Signature Analysis for the Diagnosis of Rotor Faults in Induction Motors. IEEE Trans Energy Convers 25:80-89.

22 Urresty JC, Riba JR, Romeral L (2013) Diagnosis of Inter-Turn Faults in PMSMs Operating Under Non-Stationary Conditions by applying Order Tracking Filtering. IEEE Trans Pow Electron 28:507-515.

23 Romeral L, Urresty JC, Riba JR, Garcia A (2011) Modeling of Surface-Mounted Permanent Magnet Synchronous Motors With Stator Winding Inter-Turn Faults. IEEE Trans Ind Electron 58:1576-85.

24 Tallam RM, Habetler TG, Harley RG (2002) Transient model for induction machines with stator winding turn faults. IEEE Trans Ind Appl 38: 632-637.

25 Urresty JC, Riba JR, Delgado M, Romeral L (2012) Detection of Demagnetization Faults in Surface-Mounted Permanent Magnet Synchronous Motors by means of the Zero-Sequence Voltage Component. IEEE Trans Energy Convers 27:42-51.

26 Briz F, Degner MW, Guerrero JM, Garcia P (2009) Stator Windings Fault Diagnostics of Induction Machines Operated From Inverters and Soft-Starters Using High-Frequency Negative-Sequence Currents. IEEE Trans Ind Appl 45:1637-46.

27 Akin B, Choi S, Orguner U, Toliyat HA (2011) A Simple Real-Time Fault Signature Monitoring Tool for Motor-DriveEmbedded Fault Diagnosis Systems. IEEE Trans Ind Electron 58:1990-2001.

28 Bellini A, Filippetti F, Franceschini G, Tassoni C (2000) Closed-Loop Control Impact on the Diagnosis of Induction Motors Faults. IEEE Trans Ind Appl 36:1318-29.

29 Le Roux W, Harley RG, Habetler TG (2008) Detecting faults in rotors of PM drives. IEEE Ind Appl Mag 14:23-31.

30 Kwak S (2012) Four-Leg-Based Fault-Tolerant Matrix Converter Schemes Based on Switching Function and Space Vector Methods. IEEE Trans Ind Electron 59:235-243. 